\title{
Analisis Koherensi dan Kohesi Teks Deskripsi
}

\author{
I Putu Ari Putra Maulana*, Ni Made Dhanawaty, I Made Madia \\ Prodi Sastra Indonesia, Fakultas Ilmu Budaya, Unud \\ [arikputramaulana@gmail.com] \\ Denpasar, Bali, Indonesia \\ *Corresponding Author
}

\begin{abstract}
This study was titled "Coherence and Cohesion Analysis on the Text of Description for Class X Students of Denpasar Public High School 5". The problems examined in this study are three, namely the element of coherence, the tools of lexical cohesion, and the tools of grammatical cohesion in the text description of class X students of SMA 5 Denpasar. Based on the formulation of the problem, this study aims to explain the relationship of meaning or coherence, and describe the tools of lexical and grammatical cohesion. The theory used is discourse theory, namely coherence proposed by Kridalaksana and cohesion proposed by Halliday and R. Hasan. Based on the analysis that has been done on the description text of class X students of Denpasar Public High School 5 found several things. First, in the description text of class X Denpasar Public High School 5 found an element of coherence including causal relations, means-results, reasons, backgroundconclusions, concessions, comparisons, paraphrases, amplicatives, time additives (simultaneous and successive ), non-time additives, identification, generic-specific, means-purpose, and like. Second, lexical cohesion tools found include repetition (repetition), equivalent words (synonyms), opposite words (antonyms), word sanding (collocation), and equivalence (equivalence). Third, the tools of grammatical cohesion found include reference (reference), concatenation (conjunction), lapse (elipsis).
\end{abstract}

Keywords: coherence, Cohesion, description text

\begin{abstract}
Abstrak
Penelitian ini berjudul "Analisis Koherensi dan Kohesi pada Teks Deskripsi Siswa Kelas X SMA Negeri 5 Denpasar”. Masalah yang akan dianalisis ada 3, yakni unsur koherensi, alat-alat kohesi leksikal, dan alat-alat kohesi gramatikal dalam teks deskripsi kelas X SMAN 5 Denpasar. Berdasarkan rumusan masalah tersebut, penelitian ini bertujuan menjelaskan hubungan makna atau koherensi, serta mendeskripsikan alat-alat kohesi leksikal dan gramatikal. Penelitian ini menggunakan teori wacana, yaitu koherensi oleh Kridalaksana serta kohesi yang dikemukakan oleh Halliday dan R. Hasan. Berdasarkan analisis yang telah dilakukan pada teks deskripsi siswa kelas X
\end{abstract}


SMA Negeri 5 Denpasar ditemukan beberapa hal. Pertama, dalam teks deskripsi siswa kelas X SMA Negeri 5 Denpasar ditemukan adanya unsur koherensi meliputi hubungan sebab-akibat, sarana-hasil, alasan-sebab, latarkesimpulan, kelonggaran-hasil, perbandingan, parafrastis, amplikatif, aditif waktu (simultan dan beruntun), aditif nonwaktu, identifikasi, generikspesifik, sarana-tujuan, dan ibarat. Kedua, alat-alat kohesi leksikal yang ditemukan meliputi pengulangan (repetisi), padan kata (sinonim), lawan kata (antonim), sanding kata (kolokasi), dan kesepadanan (ekuivalensi). Ketiga, alat-alat kohesi gramatikal yang ditemukan meliputi pengacuan (referensi), perangkaian (konjungsi), pelesapan (elipsis).

Kata kunci : koherensi, kohesi, teks deskripsi.

\section{Latar Belakang}

Wacana merupakan satuan bahasa yang lengkap, lebih tinggi daripada klausa dan kalimat, memiliki kohesi dan koherensi yang baik, serta mampu disampaikan secara lisan dan tertulis (Tarigan, 1987:27). Suatu wacana harus memiliki keutuhan struktur. Wacana yang utuh merupakan sebuah wacana yang lengkap, dalam artian mengandung segala aspek yang terpadu dan menyatu. Adapun aspek pengutuhan wacana terbagi ke dalam dua unsur, yakni unsur kohesi dan unsur koherensi.

Berdasarkan penyampaiannya, wacana dibedakan menjadi dua macam yakni wacana bentuk lisan dan wacana bentuk tulis. Wacana bentuk tulis adalah tipe wacana yang disalurkan melalui media bentuk tulisan. Salah satu bentuk wacana tulis adalah teks. Jenis-jenis teks yang secara umum dikenal ada deskripsi, laporan, prosedur, penceritaan, eksplanasi, eksposisi, diskusi, surat, editorial, iklan, negosiasi, anekdot, naratif, eksemplum, dan lain-lain.

Teks deskripsi merupakan teks yang memberikan penjelasan dan pemaparan tentang sebuah objek tertentu melalui kata-kata yang dapat merangsang pancaindra sehingga pembaca dapat seolah-olah menyaksikan atau merasakan sendiri objek yang dideskripsikan oleh penulis. Teks deskripsi merupakan salah satu materi pokok dalam bidang studi
Bahasa Indonesia di tingkat sekolah menengah atas (SMA) dalam kurikulum 2013.

Pada kenyataannya sekarang kemampuan siswa dalam teks deskripsi, koherensif dan kohesif belum dipakai secara menyeluruh. Begitu pula dengan masalah kurang difungsikannya satu aspek pendidikan yang sangat penting yaitu pembuatan wacana yang koheren.

Oleh karena itu, peneliti tertarik untuk meneliti SMA Negeri 5 Denpasar yang beralamat di Jln. Sanitasi Nomor 2, Sidakarya, Denpasar Selatan karena beberapa alasan. Pertama, penelitian wacana analisis koherensi dan kohesi teks deskripsi ini belum pernah dilakukan di SMA Negeri 5 Denpasar. Kedua, SMA Negeri 5 Denpasar memiliki segudang prestasi di bidang akademik dan nonakademik.

\section{Pokok Permasalahan}

Berdasarkan latar belakang di atas, dapat dirumuskan permasalahan sebagai berikut.

a) Hubungan makna atau koherensi apa yang terdapat dalam teks deskripsi siswa kelas $X$ SMA Negeri 5 Denpasar?

b) Alat-alat kohesi leksikal apa yang digunakan dalam teks deskripsi siswa kelas X SMA Negeri 5 Denpasar? 
c) Alat-alat kohesi gramatikal apa yang digunakan dalam teks deskripsi siswa kelas X SMA Negeri 5 Denpasar?

\section{Tujuan Penelitian}

Tujuan penelitian ini adalah sebagai berikut. Pertama untuk mengetahui hubungan makna atau koherensi yang terdapat pada teks deskripsi siswa kelas X SMA Negeri 5 Denpasar. Kedua untuk mengetahui alat-alat kohesi leksikal yang digunakan dalam teks deskripsi siswa kelas X SMA Negeri 5 Denpasar. Ketiga untuk mengetahui alat-alat kohesi gramatikal yang digunakan dalam teks deskripsi siswa kelas X SMA Negeri 5 Denpasar.

\section{Metode Penelitian}

Metode dalam penelitian ini adalah dengan menggunakan metode simak, kemudian diwujudkan melalui teknik catat. Pada tahap penganalisisan data digunakan metode agih dan teknik bagi unsur langsung. Dalam proses penyajian hasil penganalisisan data menggunakan metode informal.

\section{Hasil dan Pembahasan}

\subsection{Hubungan Makna atau Koherensi pada Teks Deskripsi Siswa Kelas X SMA Negeri 5 Denpasar}

Adapun teori yang digunakan untuk menganalisis koherensi tersebut adalah teori Kridalaksana (dalam Mulyana, 2005:32). Koherensi dapat terjadi pada antarkalimat dan antarparagraf. Hubungan semantis yang dimaksud dalam koherensi, yaitu hubungan sebabakibat, hubungan sarana-hasil, hubungan alasan-sebab, hubungan sarana-tujuan, hubungan latar-kesimpulan, hubungan kelonggaran-hasil, hubungan syarat-hasil, hubungan perbandingan, hubungan parafrastis, hubungan amplikatif, hubungan aditif waktu (simultan dan beruntun), hubungan aditif nonwaktu, hubungan identifikasi, hubungan generik spesifik, hubungan ibarat.

\section{a. Hubungan Sebab-Akibat}

Data [1] : ${ }^{(1)}$ Desa kelahiranku adalah sebuah desa wisata. ${ }^{(2)}$ Oleh karena itu, kelestariannya masih sangat dijaga.

\section{Analisis :}

Data (1) menunjukkan adanya hubungan sebab-akibat karena desa kelahiranku adalah sebuah desa wisata yang mengakibatkan kelestariannya masih sangat dijaga. Hubungan sebabakibat ditandai oleh kalimat ${ }^{(1)}$ sebagai sebab dan kalimat (2) sebagai akibat. Dalam data (1) hubungan sebab-akibat antarkalimat dinyatakan secara eksplisit karena menggunakan sarana kebahasaan konjungsi oleh karena itu yang secara gramatikal bermakna akibat.

\section{b. Hubungan Identifikasi}

Data [2] : ${ }^{1)}$ Pura Besakih Bali sering disebut sebagai Pura Agung Besakih. ${ }^{(2)}$ Dalam kompleks Pura Besakih terdiri dari satu pusat pura, 18 pura pendamping, 1 Pura Basukian, dan 17 pura lainnya.

\section{Analisis :}

Data (2) menunjukkan adanya hubungan identifikasi karena dalam kompleks Pura Besakih terdiri dari satu pusat pura, 18 pura pendamping, 1 Pura Basukian, dan 17 pura lainnya diidentifikasi sebagai Pura Agung Besakih. Hubungan identifikasi yang menyatakan identifikasi terdapat pada kalimat (1) dan kalimat (2) menyatakan penjelas. Dalam data (2) hubungan identifikasi antarkalimat dinyatakan secara eksplisit karena Pura Besakih diidentifikasikan dengan kompleks Pura Besakih secara gramatikal bermakna identifikasi. 


\subsection{Alat-alat Kohesi Leksikal pada Teks Deskripsi Siswa Kelas X SMA Negeri 5 Denpasar}

Teori yang digunakan dalam menganalisis permasalahan adalah teori yang dikemukakan oleh Halliday dan Hassan (dalam Mulyana, 2005:32).

\section{a. Sanding Kata (Kolokasi)}

Data [3] : ${ }^{(1)}$ Akhir-akhir ini longsor melanda kota-kota di Indonesia. ${ }^{(2)}$ Baru-baru ini longsor terjadi di wilayah Brebes, Bogor, Tasikmalaya, Cilacap, Pacitan, Malang dan Jember.

Analisis :

Data (3) menunjukkan adanya katakata yang berkolokasi. Kata Bogor, Tasikmalaya, Cilacap, Pacitan, Malang, Jember, dan Brebes adalah kata yang berkolokasi. Kata-kata tersebut berkolokasi dalam hal nama-nama kota yang berada di Indonesia.

\section{b. Sinonim}

Data [4] : ${ }^{(1)}$ Banyak keindahan pulau Bali yang bisa dinikmati salah satunya panorama bawah laut. ${ }^{(2)}$ Salah satunya Tanjung Benoa yang dikenal akan pemandangan bawah lautnya yang indah.

\section{Analisis :}

Data (4) menunjukkan adanya katakata yang memiliki hubungan kemiripan makna (sepadan), yaitu kata panorama dan kata pemandangan. Kedua kata tersebut secara makna mengungkapkan hubungan sinonim karena mengacu pada arti yang mirip. Makna kata panorama adalah 'keadaan alam yang identik dengan keindahan'. Selain itu, makna kata pemandangan adalah keadaan alam yang identik indah atau buruk dipandang'. Kata panorama dan pemandangan sama-sama bermakna 'gambaran yang melukiskan pandangan umum atau secara luas tentang sebuah objek'.

\subsection{Alat-alat Kohesi Gramatikal pada Teks Deskripsi Siswa Kelas X SMA Negeri 5 Denpasar \\ Teori yang digunakan dalam} menganalisis permasalahan adalah teori yang dikemukakan oleh Halliday dan Hassan (dalam Mulyana, 2005:32).

\section{a. Pelesapan (Elipsis)}

Data [5] : (hubungan tujuan)

1) Pantai Kuta memiliki keindahan yang sangat memukau. ${ }^{(2)}$ Pantas $\varnothing$ menjadi salah satu destinasi favorit di Bali. ${ }^{(3)}$ Tambah lagi, Ø memiliki fasilitas yang lengkap.

\section{Analisis:}

Data (5) menunjukkan adanya pelesapan (elipsis) unsur objek dalam kalimat kedua dan ketiga, yaitu pantai Kuta. Hal ini bertujuan agar dapat mengaktifkan pikiran pembaca terhadap sesuatu yang ditulis. Selain itu, agar tidak terjadi pengulangan kata yang sama. Setelah dilengkapi, kalimat tersebut menjadi "Pantai Kuta memiliki keindahan yang sangat memukau. Pantas pantai Kuta menjadi salah satu destinasi favorit di Bali. Tambah lagi, pantai Kuta memiliki fasilitas yang lengkap".

\section{a. Perangkaian (Konjungsi)}

Data [6] : (hubungan tujuan)

${ }^{(1)}$ Pada usia 12 tahun ia mulai bekerja sebagai penjual koran, buah-buahan, dan gula di kereta api. ${ }^{(2)}$ Kerja kerasnya dilakukannya semata-mata untuk membuktikan bahwa ia bukanlah orang bodoh yang bisa berpangku tangan.

\section{Analisis :}

Data (6) menunjukkan adanya pelesapan (elipsis) unsur objek dalam kalimat kedua dan ketiga, yaitu Pantai Kuta. Hal ini bertujuan agar dapat mengaktifkan pikiran pembaca terhadap sesuatu yang ditulis. Selain itu, agar tidak terjadi pengulangan kata yang sama. Setelah dilengkapi, kalimat tersebut menjadi "Pantai Kuta memiliki 
keindahan yang sangat memukau. Pantas pantai Kuta menjadi salah satu destinasi favorit di Bali. Tambah lagi, pantai Kuta memiliki fasilitas yang lengkap".

\section{Simpulan}

Berdasarkan analisis unsur koherensi dan alat-alat kohesi pada teks deskrispsi siswa kelas X SMA Negeri 5 Denpasar dapat disimpulkan, Unsur koherensi yang ditemukan pada teks deskripsi siswa kelas X SMA Negeri 5 Denpasar meliputi hubungan sebab-akibat, hubungan sarana-hasil, hubungan alasansebab, hubungan latar-kesimpulan, hubungan kelonggaran hasil, hubungan perbandingan, hubungan parafrastis, hubungan amplikatif, hubungan aditifwaktu (simultan dan beruntun), hubungan aditif nonwaktu, hubungan identifikasi, hubungan generik-spesifik, hubungan sarana tujuan, hubungan ibarat, dan hubungan syarat hasil. Berdasarkan data yang telah dianalisis terkumpul alat-alat kohesi leksikal pada teks deskripsi siswa kelas X SMA Negeri 5 Denpasar meliputi (1) Repetisi, (2) padan kata (sinonim), (3) lawan kata (antonim), (4) sanding kata (kolokasi), serta (5) kesepadanan (ekuivalensi). Selanjutnya, alat-alat kohesi gramatikal yang ditemukan pada teks deskripsi siswa kelas X SMA Negeri 5 Denpasar meliputi (1)pengacuan (referensi), yaitu pengacuan persona (berupa persona pertama, persona kedua, persona ketiga), pengacuan demonstratif, dan pengacuan komparatif, (2) penggantian (substitusi), (3) pelesapan (elipsis), yaitu dalam tataran frasa (berupa frasa verba, frasa nomina, dan frasa numeralia), dan (4) perangkaian (konjungsi), seperti hubungan waktu, hubungan syarat, hubungan tujuan, hubungan perlawanan, hubungan pemilihan, hubungan konsesif, hubungan cara, hubungan penjumlahan, hubungan penyebaban, hubungan hasil, dan hubungan komplementasi.

\section{Saran}

Berdasarkan simpulan di atas, penerapan unsur koherensi dan alat-alat kohesi yang terdapat dalam teks deskripsi siswa kelas X SMA Negeri 5 Denpasar cukup baik. Penelitian ini hanya meneliti paragraf pada teks deskrispsi siswa kelas $X$ MIPA 4 dan 9 serta IPS 1 dan 2 SMA Negeri 5 Denpasar. Akan tetapi, masih ada beberapa hal yang perlu untuk diperhatikan guna mencapai hasil yang lebih baik lagi. Berikut saran yang berkaitan dengan analisis wacana.

a) Bagi penelitian selanjutnya, diharapkan tidak hanya meneliti kohesi dan koherensi saja, tetapi juga mencari permasalahan dalam penggunaan unsurunsur bahasa.

b) Peneliti selanjutnya, diharapkan dapat menggali dan mengungkap suatu permasalahan dalam bidang wacana.

c) Penelitian analisis wacana juga dapat dilakukan pada karya sastra antara lain; puisi dan drama sehingga mampu melihat jelas perbedaan antara kohesi dan koherensi antarkalimat yang terdapat dalam jenis karya sastra tersebut.

\section{Daftar Pustaka}

Alwi, Hasan dkk. 2010. Tata Bahasa Baku Bahasa Indonesia. Jakarta: Balai Pustaka.

Brown, Gillian dan George Yule. 1983. Discourse Analysis. Cambridge: Cambridge University Press.

Darma, Yoce Aliah. 2009. Analisis Wacana Kritis. Bandung: Yrama Widya.

Departemen Pendidikan Nasional. 2008. Kamus Besar Bahasa Indonesia. Jakarta: Gramedia Pustaka Utama.

Eriyanto. 2001. Analisis Wacana, Pengantar Analisis Teks Media. Yogyakarta:LKis. 
http://yuksinau.id/teks-deskripsi-

pengertian-struktur-contoh

(diakses 18 september 2018).

Keraf, Gorys. 1984. Komposisi. Ende Flores: Nusa Indah.

Kridalaksana, Harimurti. 1982. Kamus Linguistik. Jakarta: Gramedia Pustaka Utama.

Mulyana. 2005. Kajian Wacana. Yogyakarta: Tiara Wacana.

Nisa, Hany Uswatun. 2011. "Kohesi dan Koherensi antarkalimat dalam wacana Berita di Majalah Penjebar Semangat". Skripsi Jurusan Pendidikan Bahasa dan Sastra Jawa Universitas Negeri Semarang,

Semarang.

Putri, Ida Ayu Suryantini. 2014. "Kohesi dan Koherensi Wacana Motivasi Mario Teguh Golden Ways tentang Wanita pada Stasiun Metro TV". Skripsi Jurusan Sastra Indonesia Fakultas Ilmu Budaya Universitas Udayana, Denpasar

Sudaryanto. 1993. Metode dan Aneka Teknik Analisis Bahasa. Yogyakarta: Duta Wacana University Press. 